\title{
Psychological and pedagogical aspects of simulation technology at English lessons for future engineers of the agro-industrial complex
}

\author{
Tatiana Isaeva $^{1,{ }^{*},}$ Natalia Malishevskaya ${ }^{1}$, Elena Goryunova $^{1}$, Liliya Lazareva $^{1}$, and \\ Mikhail Churikov ${ }^{1}$ \\ ${ }^{1}$ Rostov State Transport University, 2, Rostovskogo Strelkovogo Polka Narodnogo \\ Opolcheniya Sq., 344038 Rostov-on-Don, Russia
}

\begin{abstract}
During the period of COVID-19 pandemic when mostly all the universities have transferred to distant learning, the educational effect of many interactive methods partially reduced. However, simulation is underestimated by university professors and scarsely used in the educational process. Despite a profound interest in interactive methods, theoretical and practical issues of simulation still need examination, especially in the context of competence-based education. In present research pedagogical, psychological and linguistic issues of simulation are studied. Though, simulation is often referred to as a method or a game, we consider it to be an educational technology. Contrary to entertaining simulation, educational simulation used as technology usually is more than a case, because it has a structured scenario with a system of rules and prohibitions, which are created with a certain idea of forming specific competences. The practical part of the article contains a description of the empirical study of the simulation technology results used at English lessons at the technical university, which prove a high educational efficiency of simulation technology in the professional development of future engineers of agrocomplex.
\end{abstract}

\section{Introduction}

During the period of remote, and in some cases, blended learning, caused by the threat of the spread of the COVID-19 coronavirus infection, which has been lasting for the third semester, university foreign language teachers around the world have felt a decrease in the effectiveness of their classes with students. Many interactive teaching methods (games, discussions, cases, projects, etc.) have lost their liveliness and emotional intensity. Due to the technical limitations of the used electronic platforms (Zoom, Microsoft Teams, Skype, etc.) for remote classes, the teaching and developmental capabilities of these interactive teaching methods have reduced, especially in such important areas for mastering a foreign language as the development of extempore speech, speech reaction, modeling of professionallyoriented communication, interpersonal cooperation and team management [1-3].

* Corresponding author: isaeva.te@yandex.ru 
At the same time, during this period, the students have had more time to devote to independent work on mastering foreign languages [1]. Therefore, there is a need to search for such pedagogical technologies, methods and teaching aids that would be available in distance learning mode, could be used both individually and by several students, would contribute to the formation of communicative competence (including the communicative competence in studied foreign language) [3;4], and most importantly, they had a pronounced professional orientation [5], since as a result of distance learning, students of engineering specialties, including agro-industrial ones, are deprived of the opportunity to form many practical skills.

In our opinion, the interactive simulation technology, as well as the use of various professional simulators and simulation games in English possess all these qualities.

Various issues of implementation of simulation-based learning have been actively discussed in foreign studies over the past 10-15 years. Of particular interest are the studies of the possibilities of using simulations in the creation of integrated courses and interdisciplinary contents [6-8]; mastering practical skills for dynamic behaviour, collaborative actions and active use of STEM (science, technology, engineering and mathematics) in modern environment of intuitive abstractions [9-10].

At the same time, simulation technologies have not yet found wide application in the process of teaching a foreign language at the university $[7,11]$, especially when it concerns Russian universities, since many psychological and pedagogical aspects, theory and practice of their implementation in the educational process are still not sufficiently resolved.

\section{Objectives and Methods}

To the present moment, there is no unanimy among the scholars on the questions, what is simulation: a teaching method or a technology; is there any difference on theoretical level in the process of educational efficiency between mechanical and computor simulators, etc. The most acute question for us: is it possible to use entertainting or commercial simulation games and business simulators, i.e. digital products that are not exactly produced for educational purposes, in learning English.

The purpose of our research is to determine theoretical and practical aspects of using simulation technology at the English lessons at the technical university for training of future engineers for the agro-industrial complex.

The objectives of our research are the following:

1) to study the theoretical issues of simulation as an interactive method of education;

2) to find out psychological, pedagogical and linguistic efficiency of simulation technology, if any;

3) to conduct empirical study of the results of simulation technology being used at English lessons at the technical university.

The theoretical basis of our study is a competence-based approach that supposes that the main educational task is to create conditions for the students in their process of obtaining experience while independently seeking solutions of the cognitive, communicative, social, moral and other problems, having professional value.

Speaking about methodology of English teaching, we keep to the point that communicative competence can be formed only in the proces of interaction between the participants of the educational process when they understand the aims of their activity, have high motivation and are eager to work diligently on receiving necessary skills and habits.

\section{Theoretical Basis}




\subsection{The notion "simulation" as an interactive method and technology}

"Simulation" means pretended, imaginary reproduction of people's actions, speech and contacts while trying to solve some professional or problem situation. Simulation supposes modeling of an existing reality. "A simulation is a digital imitation of something real that has game characteristics: competition, rules, etc." [8]. Simulation helps to train different skills (manual, communicative, controlling, managerial, etc.), to develop certain personal qualities that are essential for future professions (attention, concentration, composure, sangfroid, etc.). It trains people not to lose courage in extreme, dangerous or unusual situations, it also teachers interfunctional activities, interaction and mutual aid.

Traditionally, simulation as an interactive professional technology is mostly popular in training specialists of risky professions who need instant reactions or exact manual actions, which are often repeated. That is why, the largest number of various simulators and simulation techniques are used in vocational training of transport specialists (pilots, locomotive and automobile drivers, maritime staff [6], medical personnel [12-13], etc.). With the development of computer technologies, mechanical stimulators have been replaced by electronic ones that added a lot of new details in the process of creating virtual reality: a better vision area, landscape, music, noises, other acting characters, levels of difficulty, etc. Computer simulation games, which originated from children's traditional games "playing house" or "playing warriors", have also become a new kind of interactive educational game and enriched the process of learning with the atmosphere of competitiveness, strong emotions, and thirst for victory.

Over time, a simulation has entered the traditional educational process of other specialties: managers [8], hospitality personnel, future teachers, etc. Nowadays, there is some experience of using simulation in teaching English and development of various speech skills for non-linguistic professions. So, Hsiao-Yun, Annie Changa et al. conducted an experiment on using simulation-based learning for improving their students' reading proficiency [12]. Charlott Sellberg and Mona Lundin demonstrated the possibilities of simulation technique in development of dialogue skills while modelling official negotiations among maritime staff [6]. The effectiveness of simulation games and professional simulators in vocabulary learning was proved by many scholars [11-12].

Many researches suppose simulation to be a method. As Juraj Camaj, Martin Kendra, and Jana Lalinská put it: "Computer simulation is a method that is used for analysis, evaluation and optimization of systems that exist or could exist. The basic process includes building a computer simulation model, abstraction, experimentation, interpretation and use of the results" [10].

Other scientists consider simulation, especially business simulation or commercial simulation, to be an educational game [5-8].

However, a large part of scholars [11-14] insist on it being a technology because simulation can combine a number of methods and activities that are used in students' education, e.g. planning, discussion, case solving, estimation of the results, etc. Besides, it is possible to single out the stages of its realization, starting from planning and task sharing and to evaluation of the results.

To overcome this disagreement, other scientists prefer to avoid direct naming and, being interested more in practical issues than in theoretical arguments, call the process "simulationbased learning" [6-12].

We consider simulation to be an educational technology. Contrary to entertaining simulation, educational simulation used as technology usually is more than a case, because it has a structured scenario with a system of rules and prohibitions, tasks and limitations, which are created with a certain idea of forming specific competences that can be transmitted into a real life. 
Together with role plays, discussions, cases and projects simulation belongs to an interactive method of teaching [8, 14-15]. Interactivity of a student with the environment modelled by electronic simulators is the main condition of foreign language acquisition [5]. However, simulation differs from other interactive methods:

- there are both group simulators and individual games that is very important for independed work and remote education [14];

- sometimes, cases become the part of simulation game, forming it content, moreover, in the process of simulation students can be involved into a discussion and a role play; that is why simulation technology can combine other interactive methods;

In the table 1 the comparison of simulation technology with other interactive methods shows a number of its advantages.

Table 1. Comparison of interactive methods and technologies.

\begin{tabular}{|c|c|c|c|}
\hline & $\begin{array}{c}\text { Simulation } \\
\text { technology }\end{array}$ & Case-study & $\begin{array}{c}\text { Role play \& } \\
\text { discussion }\end{array}$ \\
\hline $\begin{array}{c}\text { Possibilities of } \\
\text { creating reality }\end{array}$ & Various and integrated & Partial, only within the scenario \\
\hline $\begin{array}{c}\text { Recreation of real } \\
\text { modeling } \\
\text { imitative nature } \\
\text { maximum closely to the } \\
\text { surrounding reality in the } \\
\text { context of time and space }\end{array}$ & $\begin{array}{c}|c| \\
\text { Imitative technologies limited by the } \\
\text { terms and within the frames of } \\
\text { predictable results }\end{array}$ \\
\hline $\begin{array}{c}\text { Combination of } \\
\text { other interactive } \\
\text { methods }\end{array}$ & $\begin{array}{c}\text { Role play, discussion, } \\
\text { case-study }\end{array}$ & $\begin{array}{c}\text { Role play, } \\
\text { discussion }\end{array}$ & $\begin{array}{c}\text { Simulation, } \\
\text { case-study }\end{array}$ \\
\hline $\begin{array}{c}\text { Compatibility } \\
\text { with other } \\
\text { electronic } \\
\text { resources }\end{array}$ & $\begin{array}{c}\text { Internet, } \\
\text { e-mail, computer } \\
\text { presentation, } \\
\text { videoconference, } \\
\text { chats, blogs, forums, etc. }\end{array}$ & $\begin{array}{c}\text { Internet, } \\
\text { computer } \\
\text { presentation }\end{array}$ & $\begin{array}{c}\text { Videoconference, } \\
\text { chats, blogs, } \\
\text { forums }\end{array}$ \\
\hline
\end{tabular}

The disadvantages of computer simulations are their relatively high price, differences it architecture and other technical properties [14], length of some games or activities, which forces the teachers to transfer them only into students' independed work, lack of correspondence of vocabulary or phrases to to traditional texts and grammar [6].

\subsection{Psychological and pedagogical aspects of simulation technology at the English lessons}

The role of simulation technology in the professional training of future engineers [10] and specialists of the agricultural sector seems to be very significant. The possibilities of simulation used in professional training of specialists can be divided into two groups:

1) the formation of universal competencies of future specialists in accordance with Russian federal state educational standards;

2) the formation of professional competencies.

The use of simulation technology allows to solve the following tasks of competencebased learning [7-8]:

- awareness of the professional and personal significance of the final result;

- striving to practical orientation of the exercises performed; 
- the possibility of self-realization and manifestation of creativity in the course of solving problems;

- enhancing of the motivational and value attitude of students to the tasks performed;

- expansion of ideas about the world, professional activities and culture in general, including the culture of the people of the language under study;

- modernization of the content of independent educational work with the use of information technology;

- implementation of control and self-control based on the assessment tools offered by simulation technologies.

Speaking about the use of simulation in order to instill a conscious interest in the future profession and respect for working people in students, one should start with the fact that today representatives of a wide variety of professional groups work in the agricultural complex: starting from specialists directly related to agriculture (agronomist, soil scientist, zootechnician, etc.), and to engineers of various profiles (mechanical engineer, agricultural engineer, water management and land reclamation engineer, etc.), as well as specialists, as it would seem, not at all connected with agriculture. For example, thanks to the intensive development of agro- and eco-tourism in the agricultural complex, there is a need for specialists in the hospitality industry (hoteliers, guides, tourism managers, etc.). Therefore, the use of simulations in English classes can solve several problems:

- to acquaint students with the entire range of professions employed in modern agriculture; - help to feel the atmosphere of work and life of agricultural workers, to understand their rhythm of life, the peculiarity of seasonal work, etc.;

- to provide an integrated picture of the interaction and collective responsibility of various specialists and services in agriculture [6];

- to provide significant assistance to teachers of a foreign language who are not familiar with the realities of rural life and do not have complete information about the culture, production responsibilities of specialists in the agricultural sector, the names and functions of various agricultural industrial equipment.

In addition, there are studies proving the effectiveness of using simulation in order to develop students' critical thinking, since in the process of repeatedly performing simulation tasks, they have the opportunity to critically evaluate their actions, choose the most effective way, take into account the time and effort costs, determine the safest way to achieve the goal [8-13].

The opportunities of using simulation games in teaching ethical issues are underestimated. There is a common view among the teachers, and, moreover, among the university professors that videogames should not enter the educational process. In spite of this fact, the research conducted by Filipa de Sousa, Ingvill Rasmussen, and Palmyre Pierroux proves that this electronic means provides great opportunities in ethical education because using transformation of roles and teacher-led discussion the students were able to feel the consequences of different moral actions [16].

It is impossible not to mention one more advantage of using the simulation method, namely, the methods of assessing those competences that were supposed to be formed in the process of completing the task. The problem of assessing students' activities in the process of role plays, discussions, and the implementation of cases and projects has always remained very acute. There was often a pedagogical contradiction: what should be given priority in the assessment - linguistic literacy or social activity, leadership qualities, the ability to work in a team, innovative solutions, flexibility of thinking, mastery of general issues of world culture, etc. [17]. The fact is that interactive methods differ from other groups of methods: in the result of their use it is possible to create conditions for the integrated development of a number of universal and professional competencies. At the same time, we should remember that the personal awareness of the need to acquire new skills and new experience of action in 
a changed situation is of primary importance in the process of acquiring and developing competence. Therefore, skills of self-education and self-training, development of critical thinking, curiosity and a creative approach to completing the tasks of simulation assignments, etc. become the most important indicators of formed competencies [18]. As a result of the experience gained in solving problems composed by the simulator, students develop the ability to make non-standard decisions in new situations, use various electronic means and resources to find the right solution, and the ability to cooperate with other students to achieve the goal. The development of universal competencies has become one of the leading trends that determine the educational situation and personnel policy of most countries [18].

\subsection{Simulation technology and simulation games at EFL lessons}

The most popular type of simulation games and business simulators that can be used by university students of the EFL courses offers the opportunity to learn vocabulary while interacting, learning some new information and professional terms or simply playing [11].

Simulation technology possesses a number of valuable features, which answer the purposes of English learning:

- every student can repeat the vocabulary or speech patterns as many times as s/he needs to learn them; it is of special necessity when we speak of set expressions and phrases used by railway employees, marine officers or pilots in official radio-conversations;

- special dialogues-negotiations are modelled, the conduct of which is complicated by noise during radio communication, peculiarities of the national accent when pronouncing English phrases, emotional stress in the event of an emergency [6];

- the assimilation of various lexical units used to designate tools, equipment, household items, professional actions of specialists employed in agriculture, is accompanied by visual images, which contributes to better memorization and reproduction in speech;

- in addition to directly professional vocabulary, students have the opportunity to familiarize themselves with everyday phrases, jokes, English humour, mentioning of cultural objects, traditions, etc.

\section{Results}

Our research of implementing simulation technology at the English lessons for students of technical university was held in 2020 during the pandemic period in the conditions of remote learning. After the first month of remote learning in March, 2020, it has become clear that some new electronic technologies and methods capable to simulate English speaking environment and increase students' motivation are necessary.

Taking into account the variety of professions that exist in agro-complex, we decided to conduct our research at the English lessons for the students of three specialties "Operation of transport and technological machines and complexes (Automobiles and Automobile Industry)", "Tourism (Transport provision in tourism)", and "Hotel Industry" of the Rostov State Transport University.

The first problem that we faced with was to find the most suitable simulation games and professional simulators for the purposes of EFL. Basing on the research of Huifen Lin [11], we decided to use such computer simulators, as Bed \& Breakfast, Resort Hotel, Hotel Renovator and some other for future hoteliers; for future bartenders - VA-11 HALL-A (developed by Sukeban Games, Ysbryd Games) and Coffee Talk (developed by Toge Productions) in the independed work of the Humanities' students. These computer simulators are aimed at learning the hotel, restaurant and bar vocabulary; physical training of some essential skills which are used by chambermaids, bartenders or waiters; possibilities of 
solving a number of typical situational problems, where the knowledge of law, etiquette, international communication and psychology of social behaviour are required. Playing the game and serving the clients, one can listen to numerous stories and participate in the discussion.

The following simulation games: Agricultural Simulator (versions 13, 15, 18 developed by Actalogic), Farming Simulator - (versions 15 and 19 developed by Giants Software), Ranch Simulator (Excalibur Games) were suggested for independed work of the students of engineering specialty. All these simulators are advertised as realistic multiplayer agriculture management electronic tools that provide unforgettable experience of immersing into the atmosphere of a farm, harvesting, hunting and agricultural construction. Though the games differ in rules, multimedia characteristics, the number of potential players, all of them are aimed at training the gamers in reaching better agricultural results by using proper mechanisms and agricultural machines, planning the fields' occupancy, giving proper food to the cattle and poultry and so on. Besides, the games have the options of playing individually or by the group, of asking the paid advice of the character-mechanic or vetdoctor or taking independed decision in spite of the risk.

The greatest advantage of all simulators chosen for our English learning is that they model the agricultural reality - fields, farms, landscapes, mechanic workshops, etc. - on the highest multimedia level. The action is really very realistic and accompanied with music, nature sounds, real conversations, etc. There is the possibility to invest finances and buy all types of agricultural machines and tools, even to buy a railway and use it for transportation, which is of great interest for future railway engineers. There are special written scrips to help the beginner in understanding influence of weather conditions, or mechanical disfunctions on the efficiency of work.

So, there are possibilities to train all the aspects of English: speaking, listening, reading, writing / business writing, communication while playing the game and obtaining professional skills and universal competences: of international communication, tolerance, broadening of general culture, mastering of informational competence, etc.

Once a week the students wrote a short review stating their results and naming the problems of working with the simulators. We discussed these questions in the online-chat, suggested special speaking situations where they could use new vocabulary and tried to find other effective ways to check and use acquired knowledge.

After one semester of using these simulators in the students' independed work, we held the questionnaire to get the feedback of using this new interactive method. The students were asked to put a point - from 1 till 5, reflecting the efficiency of the simulators in their English learning at three stages: during independed work, for English proficiency in general and for future professional skills. The results are shown in the table 2.

As we can see from Table 2, the students express unanimous satisfaction with computer simulation during their independed work; they write: "It was unusual to play computer games as a task for English preparation"; "It was such a fun to play and to learn professional vocabulary", etc. The lowest point was put for grammar leaning: the students explain it by a very primitive grammar in stimulation games. The results of Professional skills are lower than other indicators because, as the students put it: "I am sure that my work at the hotel will differ from the tasks in the simulation game"; "I am not still sure where I will work, so I don't think that I will be able to use all these skills I've received while playing the games".

Table 2. Results of the students' questionairing on the efficiency of stimulation technology during independed work for English lessons

\begin{tabular}{|c|c|c|c|c|}
\hline Questions & $\begin{array}{c}\text { Efficiency in } \\
\text { independed work }\end{array}$ & $\begin{array}{c}\text { English } \\
\text { proficiency } \\
\text { (in general) }\end{array}$ & $\begin{array}{c}\text { Professional } \\
\text { skills }\end{array}$ \\
\hline
\end{tabular}




\begin{tabular}{|c|c|c|c|c|}
\hline 1 & New vocabulary & 4 & 3 & 3 \\
\hline 2 & $\begin{array}{l}\text { Communication } \\
\text { skills }\end{array}$ & 4 & 4 & 3 \\
\hline 3 & English grammar & 3 & 2 & 2 \\
\hline 4 & Skills in listening & 4 & 3 & 2 \\
\hline 5 & Skills in reading & 4 & 3 & 4 \\
\hline 6 & $\begin{array}{l}\text { Skills in writing / } \\
\text { business writing }\end{array}$ & 4 & 4 & 4 \\
\hline 7 & $\begin{array}{l}\text { Professional } \\
\text { skills in solving } \\
\text { communicational } \\
\text { problems }\end{array}$ & 5 & 4 & 4 \\
\hline 8 & $\begin{array}{l}\text { Professional } \\
\text { skills in solving } \\
\text { technical } \\
\text { problems }\end{array}$ & 4 & 3 & 3 \\
\hline 9 & $\begin{array}{l}\text { Experience in } \\
\text { teamwork }\end{array}$ & 2 & 3 & 3 \\
\hline 10 & $\begin{array}{l}\text { Experience of } \\
\text { new environtment } \\
\text { and culture }\end{array}$ & 5 & 5 & 4 \\
\hline
\end{tabular}

\section{Discussion}

The experience of introduction of simulation games and business simulators into the process of EFL at the university, gained during the remoted learning due to the COVID pandemic, vividly demonstrates that:

- simulation technique enriches the arsenal of interactive learning by providing the students with professional skills and terminology;

- it can become a valuable form of students' independent work, as some of simulations require rather long time to form professional skills or to go through all the stages of the game; - it enhances motivation of the students, enlarges their ideas about their future work, professional environtment and duties.

The main advantage of simulation lies in its ability to transfer the process of getting knowledge and training skills from the traditional "teacher - student" pattern to student's personalized one. The very process of choosing simulation games, the time required for mastering vocabulary or dialogues makes the student wholly responsible for his / her activity and the expected results. This idea is of utmost significance because the foreign language lessons are focused not only on communicative competence development, but lies the foundation for further vocational training and world outlook.

At the same time, there are some disadvantages, which should be taken into account while introducing simulation technology into the educational process:

- speech patterns, vocabulary and grammar of game characters are primitive, as the simulation games used by us were not specially designed for university English learners;

- students can prefer playing individually but not in a group, which hinders the development of social competences and professional experience of team-playing;

- students can decide that they are too old to play the games and stop exercising in them, preferring other ways of English communication; 
- linguistic material used in the simulators should be repeated and trained at usual English lessons, otherwise it can be forgotten soon; the problem situations should be also discussed at the lessons in order to find the best decision if the students played separately.

\section{Conclusion}

The unique situation when all the universities of the world were forced to transfer their faceto-face learning into remote learning due to the measures against COVID-19 coronavirus pandemic has required the search for new or modified methods of EFL in new conditions. After a short period of time the university professors have understood that it is impossible to use traditional methods and regular ways of communication at their English lessons - only having changed the classroom and direct contact with the students by electronic communication platforms as Zoom, Teams, Skype, Moodle and others. In the conditions when there were no any professional development courses, every university professor has tried "to invent" his / her most appropriate method of keeping interest and communication with the students.

The advantages and disadvantages of using simulation at EFL described in this paper reflect the results of a short individual research. So, it is desirable to continue the study and find the answers to numerous questions connected with the possibilities of "mixing" / "complementing" of the traditional face-to-face learning process with acquired experience of distant education when all the pandemic problems will be overcome.

However, it is evident that contrary to other abilities of remoted learning and communication platforms that were, first of all, fixed on filling of the routine of traditional language learning with computer produced multimedia sounds, videos, graphics and texts, method of simulation can boast the advantage of creation true-to life virtual reality that allows the students to fully immerse themselves into professional atmosphere, foreign language and foreign culture.

\section{References}

1. A. Reznikova, T. Kudinova, R. Patuykova, N. Olomskaya, O. Dyshekova, The «pandemic» period of the education system crisis: peculiarities of the modern telecommunication systems and messenger's implementation as the alternative didactic platforms for the linguistic disciplines teaching, E3S Web of Conferences 210, ITSE2020, 18037 (2020) doi.org/10.1051/e3sconf/202021018037

2. E. Rudenko, R. Bachieva, A. Aligadzhieva, Z. Temirhanova, A. Archilaeva, Distance learning during the pandemic: managing the challenges, E3S Web of Conferences 210, ITSE-2020, 18038 (2020) doi.org/10.1051/e3sconf/202021018038

3. O. Yarovaya, L. Yarovaya, E. Bogatskaya, Distance learning during coronavirus: problems and solutions, E3S Web of Conferences 210, ITSE-2020, 18051 (2020) doi.org/10.1051/e3sconf/202021018051

4. A. Gadakchyan, N. Kapitonova, N. Treboukhina, N. Ustinova Web environment of distance learning, E3S Web of Conferences 210, ITSE-2020, 18015 (2020) doi.org/10.1051/e3sconf/202021018015

5. S. Pozdeeva, A. Obskov, Justification of the Main Pedagogical Conditions of Interactive Teaching a Foreign Language in High School, Procedia - Social and Behavioral Sciences 206, 166 - 172 (2015) doi: 10.1016/j.sbspro.2015.10.047 
6. C. Sellberg, M. Lundin, Demonstrating professional intersubjectivity: The instructor's work in simulator-based learning environments, Learning, Culture and Social Interaction 13, 60-74 (2017) doi.org/10.1016/j.lcsi.2017.02.003

7. E. I. Polyakova, Business simulation as a means of developing intercultural competence, Procedia - Social and Behavioral Sciences 236, 289 - 294 (2016) doi: 10.1016/j.sbspro.2016.12.031

8. T. Kikota, G. Costa, R. Magalhães, S. Fernandes, Simulation games as tools for integrative dynamic learning: The case of the management course at the University of Algarve, Procedia Technology 9, 11 - 21 (2013) doi.org/10.1016/j.protcy.2013.12.002

9. F. Caglar, S. Shekhar, A. Gokhale, S. Basu, T. Rafi, J. Kinnebrew, G. Biswas, Cloudhosted simulation-as-a-service for high school STEM education, Simulation Modelling Practice and Theory 58(2), 255-273 (2015) doi.org/10.1016/j.simpat.2015.06.006

10. J. Camaj, M. Kendra, J. Lalinská, Using of simulation in technical subjects education process, Procedia - Social and Behavioral Sciences 176, 659 - 666 (2015) doi: 10.1016/j.sbspro.2015.01.524

11. H. Lin, Effectiveness of Interactivity in a Web-based Simulation Game on Foreign Language Vocabulary Learning, Procedia - Social and Behavioral Sciences 182, 313317 (2015) doi: 10.1016/j.sbspro.2015.04.772

12. H.-Yun, A. Changa, L. Chanb, B. Sirenb, The impact of simulation-based learning on students' English for Nursing Purposes (ENP) reading proficiency: A quasi-experimental study, Nurse Education Today 33(6), 584-589 (2013) doi.org/10.1016/j.nedt.2012.06.018

13. J. R.Blakeslee, Effects of high-fidelity simulation on the critical thinking skills of baccalaureate nursing students: A causal-comparative research study, Nurse Education Today 92, 104494 (2020) doi.org/10.1016/j.nedt.2020.104494

14. S. Surati, D. C. Jinwala, S. Garg, A survey of simulators for P2P overlay networks with a case study of the $\mathrm{P} 2 \mathrm{P}$ tree overlay using an event-driven simulator, Engineering Science and Technology, an International Journal 20, 705-720 (2017) doi.org/10.1016/j.jestch.2016.12.010

15. N. Berdnikova, N. Abashina, E. Klimkina, N. Manokhina, S. Dudnikova, The teaching potential of case-technology in the formation of professional competences of university students, E3S Web of Conferences 210, ITSE-2020, 18002 (2020) doi.org/10.1051/e3sconf/202021018002

16. F. de Sousa, I. Rasmussen, P. Pierroux, Zombies and ethical theories: Exploring transformational play as a framework for teaching with videogames, Learning, Culture and Social Interaction 19, 40-50 (2018) doi.org/10.1016/j.lcsi.2018.04.011

17. T. Isaeva, N. Malishevskaya, L. Cherkasova, A. Kolesnichenko, University faculty motivation to students' distant evaluation, E3S Web of Conferences 210, ITSE-2020, 18071 (2020) doi.org/10.1051/e3sconf/202021018071

18. N. Efremova, O. Shapovalova, A. Huseynova, Innovative technologies for the formation and assessment of competencies and skills in the XXI century, E3S Web of Conferences 210, ITSE-2020, 18021 (2020) doi.org/10.1051/e3sconf/202021018021 